\title{
Changed the cup, not the saucer - NFC payments in supermarkets
}

\author{
Poornigha Santhana Kumar ${ }^{1}$ Michael Bechinie ${ }^{1}$ and Manfred Tscheligi ${ }^{2}$ \\ ${ }^{1}$ USECON, 1110 Vienna, Austria \\ kumar@usecon.com, bechiniedusecon.com \\ ${ }^{2}$ University of Salzburg, 5020 Salzburg, Austria \\ manfred.tscheligiesbg.ac.at
}

\begin{abstract}
Near field communication (NFC) payments are into play for many years now. Both card and mobile NFC's are widely accepted by almost all supermarkets in many countries. The usability of NFC payments not only depends on the NFC card/mobile used but also on the payment terminal used in the supermarkets. To evaluate the usability of NFC payments, observations and exit interviews were conducted in 6 different supermarkets in Vienna, Austria. We had a total 160 observations and 179 exit interviews. The above-mentioned data was analyzed and the results portrayed that NFC payments suffer several usability issues. The results show that users face lack of proper information, lack of feedback and consistency while paying with NFCs.
\end{abstract}

Keywords: NFC Payments, usability, user study.

\section{Introduction}

NFC payments using card and mobile is replacing the traditional payment methods like cash and credit/debit card payments in many countries [1]. NFC payments outsmart the existing payment methods with its advantages [2] [3]. Since the user can pay (up till a particular limit) using NFC card/mobile by just holding them against the payment terminal, it is quicker than other payment methods and prevents attacks like shoulder surfing. The amount that can be paid using NFC card/mobile differs from various country and currency.

The acceptance of mobile payment has been studied in the literature. Some studies [4] [5] [6] also specifically study the acceptance of NFC payments. Most of these studies [4] [5] use TAM (Technology Acceptance Model) to evaluate the acceptance of mobile payment and NFC payment. Some studies also incorporate other psychological dimensions like trust [6] [7], social influence [5], perceived risk [5] and cost [5]. The acceptance of NFC payments has also been studied based on locations. [8] and [9] studies the state of NFC payments in Switzerland and Korea respectively. The above studies conclude by projecting the acceptance NFC's in those locations. Even though several studies have explored the acceptance of NFC's payments based on various dimensions, some aspect like usability and user experience of NFC remains as an unknown side in literature.

An NFC payment consists of 2 components: the NFC card/mobile and the payment terminal at the supermarket. While considering the usability of NFC payments both the 
card/mobile and the payment terminal should be considered together. Both the component should work appropriately to be usable to the users. Only a few studies [10] [11] explore the usability of the NFC payment systems. The existing studies also state that the feedback, visibility and accessibility of the NFC system should be improved. This led us to explore further in this direction.

\section{Methodology}

Here, we present the methodology we used to understand the usability of NFC payments in supermarkets. We conducted a user study in supermarkets to understand the existing practice and the hassles faced by the customers while paying with NFC card/mobile. We conducted observations and exit interviews in 6 supermarkets in Vienna for 3 hours in each supermarket. At the end of 6 days, we observed 160 customers who paid with NFC and we also received 179 exit interviews from the customers. During observation, the customers were observed on their attention to audio feedback, their attention to visual feedback and their familiarity with NFC payments. Despite the payment method used by the customers in the supermarket, they were asked for their interest in giving a short interview. Interested customers were questioned about the feedback given by the payment terminal, information provided in NFC card or mobile and were asked their reasons for using or not using NFC payments.

In exit interviews $(\mathrm{N}=179)$, we had $78(44 \%)$ male and $101(56 \%)$ female customers with the mean age of 41.69 ( $\mathrm{SD}=15.61)$. The results from observation and exit interviews are summarised in Table 1 and Table 2 respectively.

\begin{tabular}{|l|l|}
\hline Description & Number of customers \\
\hline Perceives visual feedback & $31(19 \%)$ \\
\hline Perceives audio feedback & $49(31 \%)$ \\
\hline Perceives bill generation as feedback & $66(41 \%)$ \\
\hline
\end{tabular}

Table 1. Results from observations $(\mathrm{N}=160)$ 


\begin{tabular}{|c|l|}
\hline Description & Number of customers \\
\hline $\begin{array}{c}\text { Customers who found NFC payment } \\
\text { and feedback incomprehensible }\end{array}$ & $5(3 \%)$ \\
\hline $\begin{array}{c}\text { Participants who perceived the visual } \\
\text { feedback from the payment terminal }\end{array}$ & $24(13 \%)$ \\
\hline $\begin{array}{c}\text { Participants who perceived the audio } \\
\text { feedback }\end{array}$ & $43(24 \%)$ \\
\hline
\end{tabular}

Table 2. Results from exit interviews ( $\mathrm{N}=179)$

\section{Results}

\subsection{Visual feedback}

Both the interview and observation data shows that customers were not able to perceive the visual feedback delivered by the payment terminal. When questioned about the visual feedback during exit interviews, most customers (155 customers) were not able to answer the visual feedback provided by the terminal. Some customers even wondered if the terminal will show something when they scan their card. This is clearly because customers scan their card on top of the payment terminal screen which hides screen thereby hiding the feedback provided the screen.

Since NFC payment is a new technology the terminals used in supermarkets were not designed for them exclusively. Credit/debit card was added with NFC functionality was printed with NFC symbol for users to understand that it is an NFC card. Whereas, the terminals previously used for credit/debit card payments has been just modified to support NFC payments. This difference led to unsuitable visual feedback for NFC payments.

\subsection{Audio feedback}

Compared to visual feedback, the audio feedback delivered by the payment terminal was well perceived by the customers. 49 (31\%) customers paid attention to audio feedback during observation and 43 (24\%) customers recollected the audio feedback correctly during exit interview. As using NFC payment or credit/debit card does not affect the audio feedback, it was understood by customers easily. As supermarkets can be noisy, audio feedback cannot be unfailing all the times. Even though audio feedbacks are reliable than visual feedbacks in terms of NFC payments, it should be aided with appropriate visual feedback to improve the usability of the NFC payments. 


\subsection{Bill generation as feedback}

During our observation, we noticed that customers paying with NFC also used feedback which is not from the payment terminal to know the end of the transaction. Customers while paying with NFC tend to hold their card against the payment terminal till the bill is generated. $66(41 \%)$ customers were observed to treat bill generation as a feedback. Also in exit interviews, 2 customers mentioned that they identify the end of the transaction only using the generated bill. This is because the NFC system itself does not provide enough feedback to the customers. Using bill generation as feedback overpowers the main advantage of NFC payment. It makes customers hold their card against the terminal longer thereby increasing the total time of the process.

\section{Discussion}

The above results clearly state that there is a gap between the payment terminal used and NFC payments. This gap reduces the usability of NFC payments and also suppresses its advantages. NFC payments lack proper visual feedback, inconsistency in audio feedback and prolonged payment process because of mismatched payment terminal used in the supermarkets.

\section{$5 \quad$ Limitations}

The results above are based on the study conducted only in Vienna, Austria. We also observed only the terminals used in supermarkets in Vienna. This may have geographical limitations on the data and results presented in this paper. Also, different countries using NFC payments might have other types of payment terminals installed which may or may not overcome the above-stated shortcomings.

\section{Conclusion and next steps}

To conclude, we conducted a user study to evaluate the usability of NFC payments in supermarkets in Vienna. Our study results portrayed that NFC payment suffers several usability issues because of the payment terminals used in the supermarkets. The main reason for these usability issues is using the same payment terminal used for credit/debit card payments for NFC payments also. We propose to design or redesign the payment terminal to enhance the usability of NFC payments thus aiding the success of NFC payments. As a next step, we will be designing various experience prototypes of the NFC transaction based on the user study conducted. The prototypes will then be evaluated to find a usable NFC transaction design. 


\section{$7 \quad$ Acknowledgement}

The project leading to these first results has received funding from the European Union's Horizon 2020 research and innovation program under the Marie SklodowskaCurie grant agreement No 675730 .

\section{Reference}

1. Leong, Lai-Ying, et al. "Predicting the determinants of the NFC-enabled mobile credit card acceptance: A neural networks approach." Expert Systems with Applications 40.14 (2013): 5604-5620.

2. Ok, Kerem, et al. "Current benefits and future directions of NFC services." Education and Management Technology (ICEMT), 2010 International Conference on. IEEE, 2010.

3. Massoth, Michael, and Thomas Bingel. "Performance of different mobile payment service concepts compared with a NFC-based solution." Internet and Web Applications and Services, 2009. ICIW'09. Fourth International Conference on. IEEE, 2009.

4. Schierz, Paul Gerhardt, Oliver Schilke, and Bernd W. Wirtz. "Understanding consumer acceptance of mobile payment services: An empirical analysis." Electronic commerce research and applications 9.3 (2010): 209-216.

5. Tan, Garry Wei-Han, et al. "NFC mobile credit card: the next frontier of mobile payment?." Telematics and Informatics 31.2 (2014): 292-307.

6. Lu, Yaobin, et al. "Dynamics between the trust transfer process and intention to use mobile payment services: A cross-environment perspective." Information \& Management 48.8 (2011): 393-403.

7. Boes, Kim, Larissa Borde, and Roman Egger. "The Acceptance of NFC Smart Posters in Tourism." Information and Communication Technologies in Tourism 2015. Springer International Publishing, 2015. 435-447.

8. Ondrus, Jan, and Yves Pigneur. "An assessment of NFC for future mobile payment systems." Management of Mobile Business, 2007. ICMB 2007. International Conference on the. IEEE, 2007.

9. Shin, Seungjae, and Won-jun Lee. "The effects of technology readiness and technology acceptance on NFC mobile payment services in Korea." Journal of Applied Business Research 30.6 (2014): 1615.

10. Geven, Arjan, et al. "Experiencing real-world interaction: results from a NFC user experience field trial." Proceedings of the 9th international conference on Human computer interaction with mobile devices and services. ACM, 2007.

11. Tomitsch, Martin, Thomas Grechenig, and Richard Schlögl. "Real-world tagging in the wild: On the usability and accessibility of NFC-based interactions." Workshop on Future Mobile Experiences: Next Generation Mobile Interaction and Contextualization, Co-Located with the Nordic Conference on Human-Computer Interaction, NordiCHI. 2008. 